\title{
Influence of Temperature on the Life-Cycle Dynamics of Aedes albopictus Population Established at Temperate Latitudes: A Laboratory Experiment
}

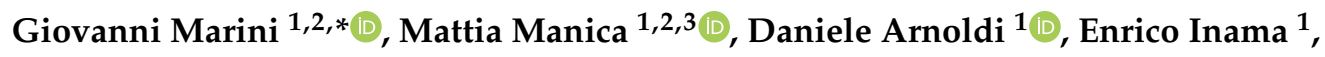 \\ Roberto Rosà $^{1,4}$ and Annapaola Rizzoli ${ }^{1}$ (D) \\ 1 Research and Innovation Centre, Department of Biodiversity and Molecular Ecology, \\ Fondazione Edmund Mach, 38010 San Michele all'Adige, Italy; mattia.manica@protonmail.ch (M.M.); \\ daniele.arnoldi@fmach.it (D.A.); enrico.inama@fmach.it (E.I.); roberto.rosa@unitn.it (R.R.); \\ annapaola.rizzoli@fmach.it (A.R.) \\ 2 Epilab-JRU, FEM-FBK Joint Research Unit, Province of Trento, 38100 Trento, Italy \\ 3 Center for Information and Communication Technology, Bruno Kessler Foundation, 38123 Trento, Italy \\ 4 Center Agriculture Food Environment, University of Trento, 38010 San Michele all'Adige, Italy \\ * Correspondence: giovanni.marini@fmach.it
}

Received: 27 October 2020; Accepted: 13 November 2020; Published: 17 November 2020

Simple Summary: Mosquitoes represent a potential major public health concern, as they are capable of transmitting several pathogens when biting humans. It is well known that temperature is a crucial factor affecting mosquito biology: for instance, warmer conditions can increase survival and fecundity. Here, we quantify the influence of different temperatures on the bionomics of Aedes albopictus, which is a mosquito species native to Southeast Asia that has been able to spread worldwide during the last forty years. We used specimens collected from northern Italy to assess if temperate individuals are characterized, possibly thanks to an adaptation process, by a different thermal response with respect to subtropical individuals. We found that immature stages are well adapted to colder temperatures, which nonetheless seem to prevent any blood-feeding activity. Adult longevity and fecundity were substantially greater at mild conditions. This thermal adaptation might increase the length of the breeding season and could allow the colonization of areas at higher altitude, resulting in an overall increased risk for potential transmission of Ae. albopictus-borne pathogens.

\begin{abstract}
The mosquito species Aedes albopictus has successfully colonized many areas at temperate latitudes, representing a major public health concern. As mosquito bionomics is critically affected by temperature, we experimentally investigated the influence of different constant rearing temperatures $\left(10,15,25\right.$, and $\left.30^{\circ} \mathrm{C}\right)$ on the survival rates, fecundity, and developmental times of different life stages of Ae. albopictus using a laboratory colony established from specimens collected in northern Italy. We compared our results with previously published data obtained with subtropical populations. We found that temperate Ae. albopictus immature stages are better adapted to colder temperatures: temperate larvae were able to develop even at $10^{\circ} \mathrm{C}$ and at $15^{\circ} \mathrm{C}$, larval survivorship was comparable to the one observed at warmer conditions. Nonetheless, at these lower temperatures, we did not observe any blood-feeding activity. Adult longevity and fecundity were substantially greater at $25^{\circ} \mathrm{C}$ with respect to the other tested temperatures. Our findings highlight the ability of Ae. albopictus to quickly adapt to colder environments and provide new important insights on the bionomics of this species at temperate latitudes.
\end{abstract}

Keywords: mosquito bionomics; mosquito dynamics; invasive species 


\section{Introduction}

Aedes albopictus is a mosquito species native to Southeast Asia that has been able to spread worldwide during the last forty years. In particular, it has successfully colonized many areas in several European countries, and it was the subject of European guidelines to contain and prevent its further spread [1,2]. Nowadays, its distribution in Europe is constantly monitored, and updated distribution maps are available [3]. Aedes albopictus represents a major public health concern in all countries where it has established since it is a competent vector of a broad range of viruses such as Zika (ZIKV), dengue (DENV), and chikungunya (CHIKV) [4,5]. The Ae. albopictus mosquito was responsible for the two largest European chikungunya outbreaks that both occurred in Italy in 2007 and 2017 [6,7], and it has been associated with the autochthonous transmission of ZIKV, CHIKV, and DENV in Croatia, France, Italy, and Spain [8-13].

Previous modeling studies predicted a further spread of Ae. albopictus in new areas [14-17], which has been confirmed by recent observations. Usually, temperature is one of the key components of such model predictions, as mosquito population dynamics (e.g., survival, development, fecundity) are critically affected by environmental temperatures [18-22]. Therefore, quantitative information on this relationship is crucial to assess the population dynamics and the potential environmental suitability for different mosquito species under climate change scenarios. However, despite their relevance in terms of rapid risk assessment for public health, quantitative estimate of such parameters under different environmental and climatic conditions are often lacking.

Several laboratory studies have been carried out to quantify the effect of different temperatures on Ae. albopictus development and survival [18,23-25], showing that warmer conditions are in general associated with shorter developmental times and very high temperatures (e.g., $35^{\circ} \mathrm{C}$ ) result in a shorter adult longevity. In addition, field experiments showed a positive correlation between abundance and temperature, suggesting that warmer temperatures may shorten developmental time or improve survival and favor mosquito spread [26,27]. However, Ae. albopictus has showed strong ecological plasticity and may in the future well adapt to colder than expected climates [28].

The study carried out by Delatte and coauthors [18] is to the best of our knowledge one of the most recent and widely referred as a source for parameter values in Ae. albopictus modeling (e.g., [29-35]). In their study, the authors investigated Ae. albopictus immature stages survival and development, adult longevity, and fecundity at different constant temperatures, ranging from 5 to $40{ }^{\circ} \mathrm{C}$, using specimens from a laboratory colony established from field-collected mosquitoes in La Réunion Island, France $\left(55^{\circ} 29^{\prime} \mathrm{S}\right.$ and $\left.47^{\circ} 51^{\prime} \mathrm{W}\right)$, which is an area characterized by a subtropical climate.

Thus, we performed further experiments to investigate whether Ae. albopictus, collected from a temperate area where it has established for more than a decade, is characterized, possibly thanks to an adaptation process, by different life traits with respect to subtropical individuals. To this aim, we replicated Delatte's experiments for a subset of temperatures using specimens from the province of Trento (northern Italy) where Ae. albopictus has been present since at least 1996 [36,37].

\section{Materials and Methods}

\subsection{Mosquito Colony}

A colony of Ae. albopictus was established in 2018 in the insectary of Fondazione Edmund Mach (San Michele all'Adige, Italy) from eggs collected in the field in the province of Trento (Italy). Adults were kept in a cage $45 \times 45 \times 45 \mathrm{~cm}$ (Bugdorm, MegaView Science Co., Ltd., Taiwan) in a climatic room at $25 \pm 1^{\circ} \mathrm{C}$ and a relative humidity (RH) of $75 \pm 5 \%$, with a photoperiod of $16 \mathrm{~L}$ :8D with $1 \mathrm{~h}$ of dawn and $1 \mathrm{~h}$ of dusk. The colony was supplied with cotton soaked in $10 \%$ common white sugar (sucrose) solution ad libitum. Twice a week, the colony was fed on cow blood for $1 \mathrm{~h}$ provided with a Hemotek blood-feeding system (Hemotek Ltd., Accrington, England). Two ovitraps lined with filter paper along the inner side as an oviposition substrate were placed inside the cage. Then, strips with 
eggs were removed and placed in plastic cups, stored in plastic bags, loosely sealed, and sprayed with water every week to maintain high RH.

\subsection{Experimental Conditions}

Environmental chambers (Proclimatic Lt 900 ACLI 4000, Imola, Italy) were used to carry out the experiments. They were programmed with a photoperiod of 12:12 (L:D) with $1 \mathrm{~h}$ of dawn and $1 \mathrm{~h}$ of dusk under four constant temperatures $\left(10 \pm 0.5,15 \pm 0.5,25 \pm 0.5\right.$ and $\left.30 \pm 0.5{ }^{\circ} \mathrm{C}\right)$. During all experiments, $\mathrm{RH}$ was controlled and fixed at $80 \pm 3 \%$, as in [18].

\subsection{Egg-Hatching Experiment}

We followed a protocol similar to the one proposed in [18]. Filter paper was collected from the colony cage within 1-2 days after placement so that eggs were only a few days different in age. Eggs of 5-9 days-old (incubated at $25^{\circ}$ and $80 \% \mathrm{RH}$ ) were placed in a group of 10 in cups (12 replicates) filled with $30 \mathrm{~mL}$ of dechlorinated water. No food was added as hatching stimuli. Cups were randomly rotated to prevent any positional effect. The 10-eggs papers were left in water for 5 days and larvae were counted daily and then removed. Every 5 days, eggs were taken out of the water and dried for 2 days. After three times, unhatched eggs were regarded as nonviable.

\subsection{Larval Survival and Developmental Time}

We followed a protocol similar to the one proposed in [18]. Eggs were placed in water for hatching at $25^{\circ} \mathrm{C}$, and subsequently, larvae less than 2-h-old were isolated in groups of 10 using small pipettes in cups filled with $120 \mathrm{~mL}$ of dechlorinated water. For each temperature, ten repetitions of 10 larvae each were monitored. Cups were randomly rotated to prevent any positional effect. Every day, exuviae and dead larvae were removed. The stage of each living larva was identified, and the number of each instar was counted. Larvae were fed daily with brewers yeast (LIEVITAL-Lesaffre Italia, Italy), with the quantity of food increasing according to the stage of development $(0.2 \mathrm{mg}$ of yeast per L1, $0.4 \mathrm{mg}$ per L2, $0.6 \mathrm{mg}$ per L3, and $0.8 \mathrm{mg}$ per L4). At the beginning of pupation, pupae were isolated, and then the number of male and female adults was counted.

\subsection{Adult Longevity and Gonotrophic Cycle}

Larvae were reared at $25^{\circ} \mathrm{C}$ and $80 \% \mathrm{RH}$ in $500 \mathrm{~mL}$ plastic cups filled with $250 \mathrm{~mL}$ of dechlorinated water and were fed daily following the protocol described above. After emergence, adult mosquitoes (males and females) of the same age (less than 12-h old) were isolated in a $22 \times 22 \times 22 \mathrm{~cm}$ cage with $10 \%$ common white sugar solution ad libitum and left together 3-4 days for free mating. After this period, females were allowed to feed on cow blood provided by Hemotek blood-feeding system. Then, one male and one engorged female of the same age were isolated as a couple in a cage with an ovitrap filled with $250 \mathrm{~mL}$ of dechlorinated water, added with $50 \mathrm{~mL}$ of grass infusion, and lined with filter paper as oviposition substrate. A piece of cotton, soaked with $10 \%$ sugar solution, was provided to each cage and replaced twice a week. Twice a week, cow blood was offered to each female by Hemotek and, immediately after, every female was observed to see if they were fed. The presence of laid eggs on the filter paper and dead male and/or female were checked daily. Eggs, if present, were counted and removed. Experiments were carried out with 20 couples for each tested temperature $\left(10,15,25\right.$, and $\left.30^{\circ} \mathrm{C}\right)$.

\subsection{Statistical Analysis}

We considered the following quantities: (i) survival and (ii) developmental times of eggs and immature stages (four larval instars and pupa); (iii) female longevity, (iv) number of eggs laid by an adult female, (v) number of gonotrophic cycles and (vi) gonotrophic cycle length. We compared all these quantities at different tested temperatures. We applied a Bayesian approach by fitting through a 
Markov Chain Monte Carlo technique [38] a Poisson distribution for developmental times, longevity, number of laid eggs, number and length of the gonotrophic cycles, and a binomial distribution for survival rates. Then, we sampled 10,000 values from the posterior distribution of the parameter of interest (for instance, the mean duration of development from L1 to A) for two tested temperatures, computed the differences between the two distributions, and assessed the probability of drawing zero from the distribution of differences. Finally, we analyzed adult survival using a Weibull model (age-dependent survival), as in [18]. Then, we stochastically simulated the population outcome of 1000 initial eggs at two different temperatures $\left(25\right.$ and $\left.30^{\circ} \mathrm{C}\right)$ to assess the expected number of emerging adults, time of development, adult longevity, and fecundity. Additional methodological details and results, including histograms of the estimated posterior distributions, are reported in Appendix A.

We also tested whether our observations differed significantly from the ones for subtropical Ae. albopictus reported in [18]. Specifically, for survival rates, developmental times, number of laid eggs, and number and length of the gonotrophic cycles, we sampled 10,000 values from the posterior distribution of the parameter of interest (for instance, the mean duration of development from L1 to A at a specific temperature) and evaluated whether the averages presented for subtropical Ae. albopictus in [18] lie in the 95\% Confidence Intervals (CI) of the estimated posterior distributions.

\section{Results}

\subsection{Survivorship and Length of Development of Eggs and Immature Stages}

The temperate eggs hatching rate is increasingly higher at hotter temperatures. At $10{ }^{\circ} \mathrm{C}$, we observed no hatching activity, and no larvae reached the third instar stage, but we can note that $38 \%$ of the initial individuals passed to the second instar stage, taking on average more than one month (about 37 days). We observed a similar fraction of temperate first instar larvae developing successfully into adults at 15,25 , and $30^{\circ} \mathrm{C}$ (see Table 1 and Figure 1 ).

We did not find statistical evidence of differences in survivorship at $30^{\circ} \mathrm{C}$ between temperate and subtropical eggs ( $p$-value $=0.05$ ), while at 10,15 , and $25^{\circ} \mathrm{C}$, temperate eggs are characterized by a substantially ( $p$-values $<0.001$ ) lower hatching rate with respect to subtropical ones. While at $10^{\circ} \mathrm{C}$ we observed some temperate larval development, all L1 subtropical individuals died before becoming L2. Overall, at $15{ }^{\circ} \mathrm{C}, 73 \%$ of the initial temperate larvae became adults, while for subtropical Ae. Albopictus, this percentage was significantly lower $(50 \%, p$-value $<0.001)$ (see Table 1 and Figure 1$)$.

There was no statistical evidence of substantial differences in the observed length of time between the immersion of eggs in water and hatching response at different temperatures. Conversely, the duration of development from L1 to adult is significantly different ( $p$-values $<0.001)$, ranging on average from more than a month ( 35 days) at $15^{\circ} \mathrm{C}$ to about one week at $30^{\circ} \mathrm{C}$ (see Table 2 and Figure 1).

Temperate eggs hatch significantly faster $(p$-values $<0.05)$ than subtropical ones at all tested temperatures. The duration of development from L1 to adult is on average significantly shorter for subtropical larvae at 15 ( $p$-value $<0.01)$ and $25^{\circ} \mathrm{C}(p$-value $<0.001)$, while conversely, at $30^{\circ} \mathrm{C}$, temperate larvae take on average substantially less time $(p$-value $<0.001)$ to become adults (see Table 2 and Figure 1 ). 
Table 1. Temperate Ae. albopictus immature survival. Survival rate (as fraction), with standard error, from hatching to emergence of temperate (TE) and subtropical (ST) Ae. albopictus maintained at four constant temperatures: $10,15,25$, and $30^{\circ} \mathrm{C}$.

\begin{tabular}{|c|c|c|c|c|c|c|c|c|c|c|c|c|c|c|c|c|c|c|}
\hline \multirow{2}{*}{$\mathrm{T}\left({ }^{\circ} \mathrm{C}\right)$} & \multicolumn{2}{|c|}{ Eggs (n) } & \multicolumn{2}{|c|}{ Egg-L1 } & \multicolumn{2}{|c|}{ L1 (n) } & \multicolumn{2}{|c|}{ L1-L2 } & \multicolumn{2}{|c|}{ L2-L3 } & \multicolumn{2}{|c|}{ L3-L4 } & \multicolumn{2}{|c|}{ L4-Pupae } & \multicolumn{2}{|c|}{ Pupae-Adult } & \multicolumn{2}{|c|}{ L1-Adult } \\
\hline & TE & ST & TE & ST & TE & ST & TE & ST & TE & ST & TE & ST & TE & ST & TE & ST & TE & ST \\
\hline 10 & 120 & 100 & 0 & $0.04 \pm 0.02$ & 100 & 80 & $0.38 \pm 0.05$ & 0 & 0 & 0 & 0 & 0 & 0 & 0 & 0 & 0 & 0 & 0 \\
\hline 15 & 120 & 110 & $0.02 \pm 0.01$ & $0.08 \pm 0.03$ & 100 & 80 & $0.98 \pm 0.01$ & $0.89 \pm 0.04$ & $0.99 \pm 0.01$ & $0.93 \pm 0.03$ & 1 & $0.86 \pm 004$ & $0.98 \pm 0.01$ & $0.84 \pm 0.05$ & $0.77 \pm 0.04$ & $0.83 \pm 0.05$ & $0.73 \pm 0.04$ & $0.5 \pm 0.06$ \\
\hline 25 & 120 & 130 & $0.23 \pm 0.04$ & $0.49 \pm 0.04$ & 100 & 80 & $0.97 \pm 0.02$ & $0.93 \pm 0.03$ & $0.99 \pm 0.01$ & $0.95 \pm 0.03$ & $0.99 \pm 0.01$ & $0.96 \pm 0.02$ & $0.99 \pm 0.01$ & $0.97 \pm 0.02$ & $0.86 \pm 0.04$ & $0.94 \pm 0.03$ & $0.81 \pm 0.04$ & $0.76 \pm 0.05$ \\
\hline 30 & 120 & 140 & $0.44 \pm 0.05$ & $0.51 \pm 0.04$ & 100 & 80 & $0.97 \pm 0.02$ & $0.88 \pm 0.04$ & $0.99 \pm 0.01$ & $0.99 \pm 0.01$ & $0.98 \pm 0.01$ & $0.96 \pm 0.02$ & $0.9 \pm 0.03$ & $0.91 \pm 0.04$ & $0.84 \pm 0.04$ & $0.9 \pm 0.04$ & $0.71 \pm 0.05$ & $0.68 \pm 0.05$ \\
\hline
\end{tabular}

Table 2. Temperate Ae. albopictus developmental time. Length of time between immersion of eggs in water and hatching response and duration of development (mean and standard error in days) of each stage of temperate (TE) and subtropical (ST) Ae. albopictus maintained at four constant temperatures: $10,15,25$, and $30{ }^{\circ} \mathrm{C}$.

\begin{tabular}{|c|c|c|c|c|c|c|c|c|c|c|c|c|c|c|}
\hline \multirow{2}{*}{$\mathrm{T}\left({ }^{\circ} \mathrm{C}\right)$} & \multicolumn{2}{|c|}{ Eggs-L1 } & \multicolumn{2}{|c|}{ L1-L2 } & \multicolumn{2}{|c|}{ L2-L3 } & \multicolumn{2}{|c|}{ L3-L4 } & \multicolumn{2}{|c|}{ L4-Pupae } & \multicolumn{2}{|c|}{ Pupae-Adult } & \multicolumn{2}{|c|}{ L1-Adult } \\
\hline & $\mathrm{TE}$ & ST & TE & ST & TE & ST & $\mathrm{TE}$ & ST & $\mathrm{TE}$ & ST & TE & ST & TE & ST \\
\hline 10 & & $2.0 \pm 0.0$ & $37.4 \pm 0.7$ & & & & & & & & & & & \\
\hline 15 & $2.0 \pm 0.1$ & $7.4 \pm 1.8$ & $5.8 \pm 0.1$ & $5.6 \pm 0.3$ & $5.1 \pm 0.2$ & $3.3 \pm 0.2$ & $7.0 \pm 0.1$ & $4.6 \pm 0.2$ & $16.7 \pm 0.4$ & $13.4 \pm 0.8$ & $10.7 \pm 0.3$ & $8.7 \pm 0.6$ & $36.8 \pm 0.5$ & $35 \pm 0.9$ \\
\hline 25 & $3.8 \pm 0.4$ & $4.5 \pm 0.7$ & $2.5 \pm 0.1$ & $2.1 \pm 0.2$ & $2.0 \pm 0.1$ & $1.2 \pm 0.2$ & $2.4 \pm 0.1$ & $1.2 \pm 0.1$ & $5.0 \pm 0.1$ & $3.3 \pm 0.2$ & $3.5 \pm 0.1$ & $2.7 \pm 0.1$ & $12.7 \pm 0.2$ & $10.4 \pm 0.7$ \\
\hline 30 & $3.2 \pm 0.3$ & $6.7 \pm 0.7$ & $2.0 \pm 0.0$ & $1.4 \pm 0.1$ & $1.1 \pm 0.0$ & $1.3 \pm 0.1$ & $1.4 \pm 0.1$ & $1.4 \pm 0.2$ & $3.5 \pm 0.1$ & $3.0 \pm 0.3$ & $1.9 \pm 0.0$ & $1.9 \pm 0.1$ & $7.6 \pm 0.1$ & $8.8 \pm 0.6$ \\
\hline
\end{tabular}



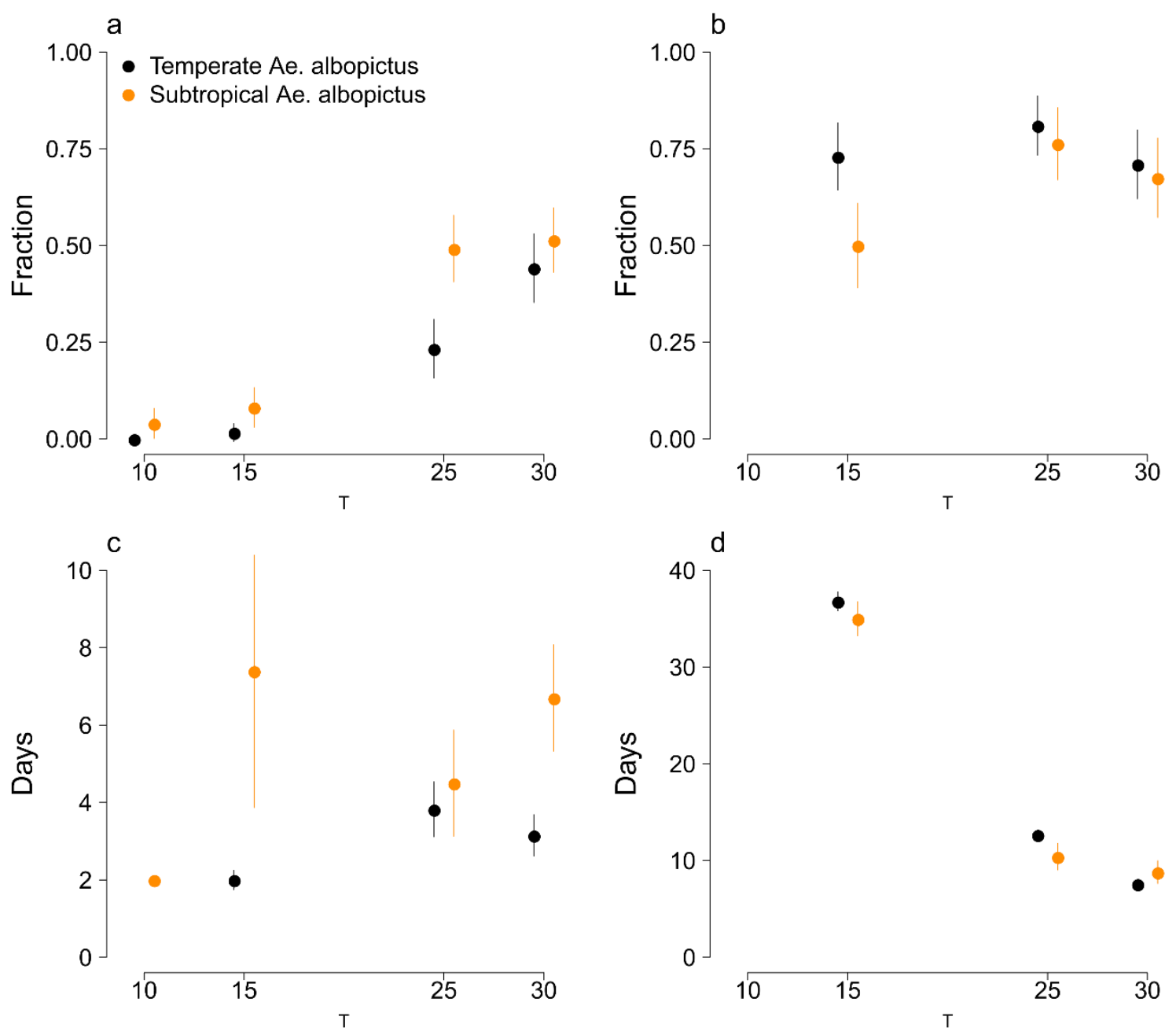

Figure 1. Comparison between temperate Ae. albopictus (black) and subtropical Ae. albopictus (orange) results for each tested temperature $\left(10,15,25\right.$, and $\left.20^{\circ} \mathrm{C}\right)$. (a): Fraction of hatched eggs; (b): fraction of L1 larvae that successfully reached the adult stage; (c): length of time between immersion of eggs in water and hatching response; (d): duration of development from L1 to adult. Points: average values. Vertical lines: 95\% Confidence Intervals (average $\pm 1.96 \cdot \mathrm{SE}$ ).

\subsection{Adult Life Expectancies}

The average longevity of temperate female adults differs at different temperatures, being considerably shorter at low temperatures (less than a week at $10^{\circ} \mathrm{C}$ ). It is interesting to note that at $10{ }^{\circ} \mathrm{C}$, all females died within 10 days, whereas at $25^{\circ} \mathrm{C}$, all individuals survived at least one month (see Table 3 and Figure 2).

Table 3. Temperate Ae. albopictus adult longevity. Longevity (days) of Ae. albopictus temperate adult females maintained at four constant temperatures: $10,15,25$, and $30{ }^{\circ} \mathrm{C}$.

\begin{tabular}{ccc}
\hline T $\left({ }^{\circ} \mathbf{C}\right)$ & Mean \pm SE (Days) & Range (min-max) (Days) \\
\hline 10 & $5.7 \pm 0.4$ & $2-10$ \\
15 & $27.9 \pm 2.0$ & $8-45$ \\
25 & $64.5 \pm 3.8$ & $32-92$ \\
30 & $53.5 \pm 4.7$ & $14-86$ \\
\hline
\end{tabular}




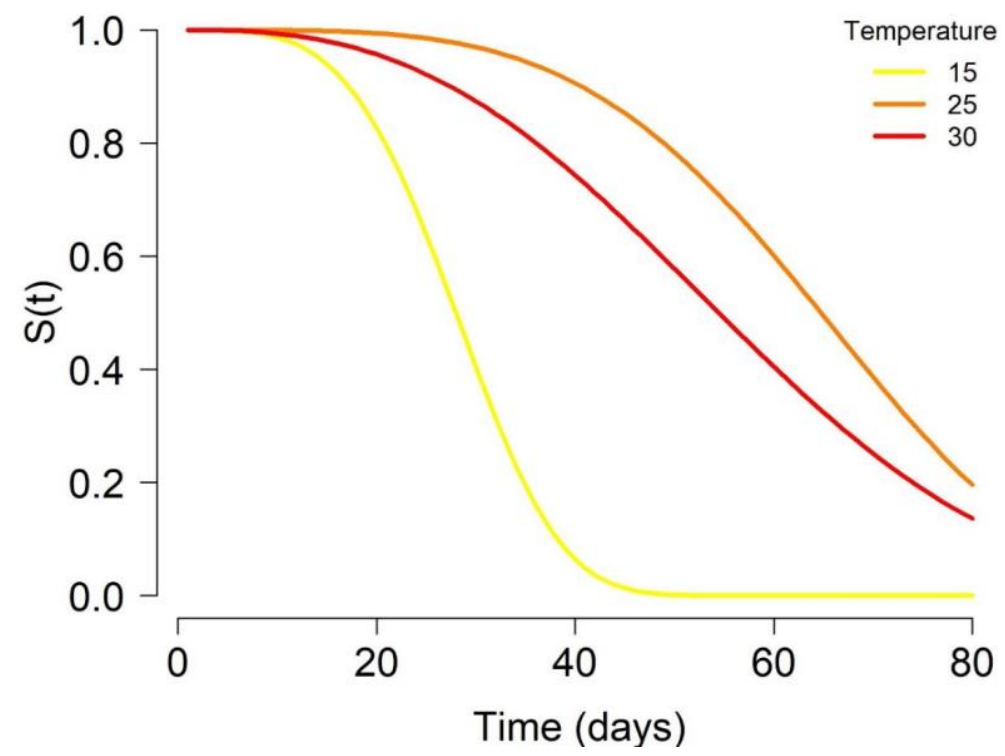

Figure 2. Survival rate of Ae. albopictus females adjusted to the Weibull's model at temperatures of 15, 25 , and $30^{\circ} \mathrm{C}$.

Subtropical mosquitoes showed a higher survival at $30^{\circ} \mathrm{C}$ than at $25^{\circ} \mathrm{C}$ [18], while for temperate Ae. Albopictus, we found the opposite.

\subsection{Gonotrophic Cycles and Egg Laying}

At $10{ }^{\circ} \mathrm{C}$, blood-feeding activity was not observed. At $15^{\circ} \mathrm{C}$, only two temperate females took a bloodmeal, but they did not lay any egg. At this temperature, we observed females completing the first gonotrophic cycle without taking blood (autogeny), as three individuals laid 3, 7, and 11 eggs, respectively. Conversely, at higher temperatures, all temperate females completed at least one gonotrophic cycle after taking a blood meal. Our results did not show any statistical differences between the gonotrophic cycle length at 25 and $30{ }^{\circ} \mathrm{C}$ ( $p$-value $\left.>0.05\right)$, but at $25{ }^{\circ} \mathrm{C}$, there is strong statistical evidence that substantially fewer eggs were laid ( $p$-value $<0.001)$. However, on average, a female completed 7.9 cycles at $25{ }^{\circ} \mathrm{C}$ and only 1.75 at $30{ }^{\circ} \mathrm{C}$ (Table 4 ).

Table 4. Temperate Ae. albopictus fecundity. Duration of gonotrophic cycle (mean and standard error in days) and number of eggs (mean and standard error) for temperate Ae. albopictus at 25 and $30{ }^{\circ} \mathrm{C}$.

\begin{tabular}{|c|c|c|c|c|c|c|c|c|}
\hline & $\mathbf{n}$ & $\begin{array}{c}\text { Duration } \\
\text { (Mean } \pm \text { SE) }\end{array}$ & $\begin{array}{l}25^{\circ} \mathrm{C} \\
\text { Minimum } \\
\text { Duration }\end{array}$ & $\begin{array}{l}\text { Number of Eggs } \\
(\text { Mean } \pm \text { SE) }\end{array}$ & $\mathbf{n}$ & Mean & $\begin{array}{c}30^{\circ} \mathrm{C} \\
\text { Minimum } \\
\text { Duration }\end{array}$ & $\begin{array}{c}\text { Number of Eggs } \\
(\text { Mean } \pm \text { SE) }\end{array}$ \\
\hline Cycle 1 & 20 & $4.2 \pm 0.1$ & 4 & $31.7 \pm 2.0$ & 20 & $3.1 \pm 0.1$ & 2 & $55.9 \pm 4.0$ \\
\hline Cycle 2 & 20 & $4.0 \pm 0.0$ & 3 & $40.1 \pm 2.3$ & 12 & $3.3 \pm 0.2$ & 2 & $55.0 \pm 8.2$ \\
\hline Cycle 3 & 20 & $3.0 \pm 0.0$ & 3 & $40.8 \pm 2.1$ & 3 & $4.3 \pm 0.9$ & 3 & $60.7 \pm 13.2$ \\
\hline Cycle 4 & 20 & $4.0 \pm 0.0$ & 4 & $40.4 \pm 2.3$ & & & & \\
\hline Cycle 5 & 17 & $3.0 \pm 0.0$ & 3 & $39.4 \pm 2.5$ & & & & \\
\hline Cycle 6 & 16 & $3.6 \pm 0.2$ & 3 & $31.6 \pm 4.7$ & & & & \\
\hline Cycle 7 & 16 & $3.9 \pm 0.1$ & 3 & $30.0 \pm 3.5$ & & & & \\
\hline Cycle 8 & 13 & $4.2 \pm 0.4$ & 3 & $25.4 \pm 5.0$ & & & & \\
\hline Cycle 9 & 9 & $4.1 \pm 0.1$ & 4 & $29.4 \pm 8.3$ & & & & \\
\hline Cycle 10 & 5 & $4.2 \pm 0.2$ & 4 & $19.0 \pm 0.4$ & & & & \\
\hline Cycle 11 & 2 & $7.5 \pm 2.5$ & 5 & $6.0 \pm 3.0$ & & & & \\
\hline Mean & & $3.8 \pm 0.1$ & & $34.3 \pm 1.2$ & & $3.3 \pm 0.1$ & & $56.0 \pm 3.7$ \\
\hline
\end{tabular}

With respect to subtropical mosquitoes [18], at $25^{\circ} \mathrm{C}$, on average, a temperate female completes a higher number of gonotrophic cycles ( $p$-value $<0.001)$, which are also significantly shorter. Conversely, at $30^{\circ} \mathrm{C}$, on average, a temperate female completes a substantially smaller number of gonotrophic cycles 
( $p$-value $<0.001$ ), which nonetheless last similarly to subtropical ones. Finally, at both temperatures, we found temperate mosquitoes to lay substantially fewer eggs with respect to subtropical females.

\subsection{Population Dynamics Simulation}

At $25^{\circ} \mathrm{C}$, on average, 193 adults (95\%CI: 127-264) emerge from 1000 initial eggs, taking on average 16.5 days (95\%CI: 9-25) under lab conditions. Conversely, at $30{ }^{\circ} \mathrm{C}$, adults emerge faster (mean: 10.8 days, $95 \%$ CI: 5-18) and with a higher rate (mean: 311 individuals, 95\%CI: 234-385), but they lay fewer eggs. In fact, at $25^{\circ} \mathrm{C}$, all emerged females are expected to lay on average about 25,000 eggs during their lifetime, while at $30^{\circ} \mathrm{C}$, this number decreases to about 15,500 .

\section{Discussion}

Cold temperatures have been successful in shielding temperate area to Ae. albopictus establishment, in particular regarding survival between years and overwintering [14,39]. However, in our study, we found that after 20 years from invasion, temperate immature individuals have successfully adapted to colder conditions compared to subtropical populations. For instance, we found that at $15{ }^{\circ} \mathrm{C}$, temperate eggs hatch faster. Nonetheless, $10{ }^{\circ} \mathrm{C}$ is still a lower threshold for survival, as no larval specimen survived long enough to develop into adults when kept at such temperature. This is consistent with previous findings showing that $13^{\circ} \mathrm{C}$ is the temperature threshold necessary to initiate activity in adult female mosquitoes [36].

Nevertheless, it is interesting to note that at $10{ }^{\circ} \mathrm{C}, 38 \%$ of the first instar larvae were able to develop in L2, while at this temperature, subtropical ones did not survive beyond this stage. This capability to develop earlier in the season when temperatures are still low may increase the length of the breeding season, thus potentially impacting on the planning of control intervention and surveillance. Moreover, this adaptation could let Ae. albopictus colonize areas at higher altitude, where spring temperatures are generally colder with respect to lower areas. During temperate springs and summers, such low temperatures are likely to occur, even though only for a few days, but therefore, they might be not so detrimental to larval development. For instance, in the Trento municipality, the average June daily temperature between 2010 and 2019 was $20.9^{\circ} \mathrm{C}$, ranging between 12.3 and $30.1{ }^{\circ} \mathrm{C}$. On the other hand, in this geographical area, summers are not too warm. In fact, between 2010 and 2019, only 3 days recorded an average temperature higher than $30^{\circ} \mathrm{C}[40]$.

While subtropical adult average longevity was longer at $30^{\circ} \mathrm{C}$ than at $25^{\circ} \mathrm{C}$, in our temperate populations we found the opposite. Another striking difference is the substantially higher fecundity at $25^{\circ} \mathrm{C}$, which is driven especially by the larger average number of gonotrophic cycles completed at such temperature. In natural conditions, this might be reflected with a greater than expected biting rate, with important public health implications. For instance, a crucial risk measure is given by the basic reproductive number $R_{0}$, which is defined as the expected number of secondary infections that arise when a single infective host is introduced into a fully susceptible host population through pathogen transmission by the vector (see, for instance, [41]). A higher biting rate translates into a larger $\mathrm{R}_{0}$, thus dramatically affecting for instance the probability of occurrence of an outbreak and its final size. Nonetheless, we need to remark that our experiment protocol was not exactly identical to the one followed by Delatte and coauthors. In fact, subtropical mosquitoes were offered a blood meal from an anesthetized mouse every day, while, due to logistic constraints, we offered cow blood twice a week via Hemotek. Moreover, we should note that adult survival under laboratory rather than natural conditions may have been inflated due to the availability of food and the absence of both predation and host defensive mechanisms against blood feeding.

The developmental times of aquatic stages are important for the correct planning of larvicide interventions. The vast majority of authorized larviciding products in Europe target specific stages (for instance, first and second larval instar), and their effectiveness could last up to 3/4 weeks after treatment under common use [42]. However, a short developmental time may take advantage of any 
delay in larvicide application, as well as cause a selection of small temporary breeding sites that are not suitable for larvicide interventions.

The use of a lab colony, even if mosquitoes were recently collected from the field, and the experimental conditions may have inflated survival rates, for instance thanks to a lack of predation or shortened developmental times, as there was no excessive competition for resources and no temperature fluctuation compared to field condition. Indeed, constant rearing conditions, as in the laboratory, might increase mosquito longevity and fecundity. Although these are clear limitations, they are widely accepted, as the study of such quantities in field conditions is extremely difficult. To overcome these issues, an interesting modeling framework to directly estimate such parameters from field-monitoring data was recently proposed [43]. However, even if that approach does allow for the estimation of biological parameters, it adds more complexity as many factors, ranging from computational issues to availability of meteorological data or specimen dispersal, are introduced.

Possible future studies might investigate adaptation in overwintering capability. Given our results for immature and adult specimens, it is likely that diapausing temperate eggs are more resistant to colder temperatures, as it was proven in North America [44].

Several mathematical models have been developed to study Ae. albopictus population dynamics and the transmission of viruses such as ZIKV, CHIKV, or DENV, and most of them explicitly incorporate temperature-dependence $[30,31,34,45]$. Other kinds of studies aimed at identifying new areas of potential invasion, usually considering temperature as one of the main predictors [14-17,46]. Therefore, our findings might be helpful to better tailoring such models at temperate latitudes, providing new important insights on the adaptation of this species to colder climate and on the likelihood of pathogen transmission, such as ZIKV, CHIKV, or DENV.

\section{Conclusions}

Aedes albopictus adaptation to colder habitats may have critical consequences for European public health safety by exposing previously unaffected areas to the potential transmission of arboviruses. In this study, we provided new important evidence on how such an adaptation process is occurring in temperate conditions by compiling additional knowledge regarding the life cycle features of Ae. albopictus. This adaptation might increase the length of the breeding season and could allow the colonization of areas at higher altitude, resulting in an overall increased risk for the potential transmission of Ae. albopictus-borne pathogens.

Author Contributions: Conceptualization, G.M., M.M. and D.A.; formal analysis, G.M. and M.M.; investigation, D.A. and E.I.; writing—original draft preparation, G.M.; writing—review and editing, G.M., M.M., D.A., E.I., R.R., A.R. All authors have read and agreed to the published version of the manuscript.

Funding: This work was partially funded by the European Union's Horizon 2020 Research and Innovation Programme under grant number 734548 (project: ZIKAlliance) and 874850 (project: MOOD) and is catalogued as MOOD 001. The contents of this publication are the sole responsibility of the authors and don't necessarily reflect the views of the European Commission.

Acknowledgments: The work was done within the framework of AIM-COST Action CA17108 (www.aedescost.eu).

Conflicts of Interest: The authors declare no conflict of interest.

\section{Appendix A.}

\section{Appendix A.1. Bayesian Fitting of the Posterior Distributions of Life History Parameters}

We applied a Bayesian approach by fitting through a Markov Chain Monte Carlo technique a Poisson distribution for developmental times, longevity, number of laid eggs, number and length of the gonotrophic cycles, and a binomial distribution for survival rates.

For instance, for each temperature $\mathrm{T} \in\left\{10,15,25,30^{\circ} \mathrm{C}\right\}$, we had a set of observed duration of development from $\mathrm{L} 1$ to $\mathrm{A} \tau_{L 1-A}(T)_{i}, i=1, \ldots k(T)$, where $k(T)$ is the number of emerging adults, 
which is different across the tested temperatures. Thus, the likelihood of recording our observations assuming they belong to a Poisson distribution with average $\lambda$ is

$$
L=\prod_{i=1}^{k(T)} e^{-\tau_{L 1-A}(T)_{i}} \cdot \frac{\tau_{L 1-A}(T)_{i}^{\lambda}}{\lambda !} .
$$

Recalling that such experiment was conducted using $\mathrm{N}$ cups with $n$ initial L1 specimens, we have $k(T)=\sum_{i=1}^{N} k_{i}(T)$, where $k_{i}(T)$ is the number of emerging adults in cup $i$. Thus, the likelihood of observing the recorded survivals assuming they belong to a binomial distribution with probability $p$ is

$$
L=\prod_{i=1}^{N}\left(\begin{array}{c}
n \\
k_{i}(T)
\end{array}\right) p^{k_{i}(T)}(1-p)^{n-k_{i}(T)} .
$$

The posterior distributions of $\lambda$ and $p$, denoted by $\Lambda$ and P respectively, were obtained by using random-walk Metropolis-Hastings sampling approach and normal jump distributions [38]. A total of 100,000 iterations were performed and a burn-in period of 5000 steps was chosen.

Afterwards, if for instance, we wanted to test whether the average duration of development from L1 to $\mathrm{A}$ at 25 and $30^{\circ} \mathrm{C}$ were substantially different, we randomly extracted 10,000 values from the two respective posterior distributions $\Lambda_{\mathrm{L1}-\mathrm{A}}(25)$ and $\Lambda_{\mathrm{L1}-\mathrm{A}}(30)$, computed the differences $\mathrm{x}_{\mathrm{i}}$, i.e., $\mathrm{x}_{\mathrm{i}}=\left(\lambda_{\mathrm{i}}(30)\right.$ $\left.-\lambda_{\mathrm{i}}(25)\right)_{\mathrm{i}=1, \ldots, 10,000}$, and evaluated the probability for the two distributions to be similar as

$$
q=\min (P(x \leq 0), 1-P(x \leq 0)) .
$$

If $q<0.05$, we considered the two distributions to be statistically different.

Finally, to assess if the average values reported for subtropical Ae. albopictus in [18] are significantly different from our estimates, we estimated the probability of observing the subtropical values given our results. For instance, if the average duration of development from $\mathrm{L} 1$ to $\mathrm{A}$ at $25^{\circ} \mathrm{C}$ was $s$ days for subtropical mosquitoes, we evaluated the probability of observing the subtropical value $s$ given our posterior distribution $\Lambda_{\mathrm{L} 1-\mathrm{A}}(25)$ as

$$
q=\min (P(\lambda \leq s), 1-P(\lambda \leq s)) .
$$

If $q<0.05$, we considered the two estimates to be statistically different.

The estimated posterior distributions for some quantity of interest are shown in Figures A1-A8, together with the available average observations for subtropical Ae. albopictus as reported in [18].
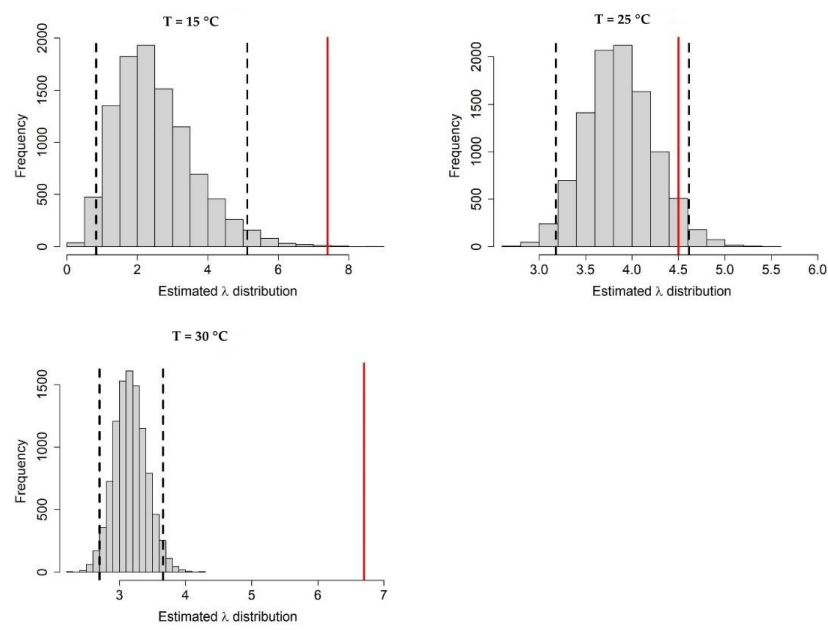

Figure A1. Estimated posterior distributions of $\Lambda_{\mathrm{E}}(\mathrm{T})$, the average length of time (days) between immersion of eggs in water and hatching response at 15,25 , and $30^{\circ} \mathrm{C}$. Dashed black lines represent the 2.5 and 97.5 quantiles. Solid red lines represent the average value for subtropical Ae. albopictus. 

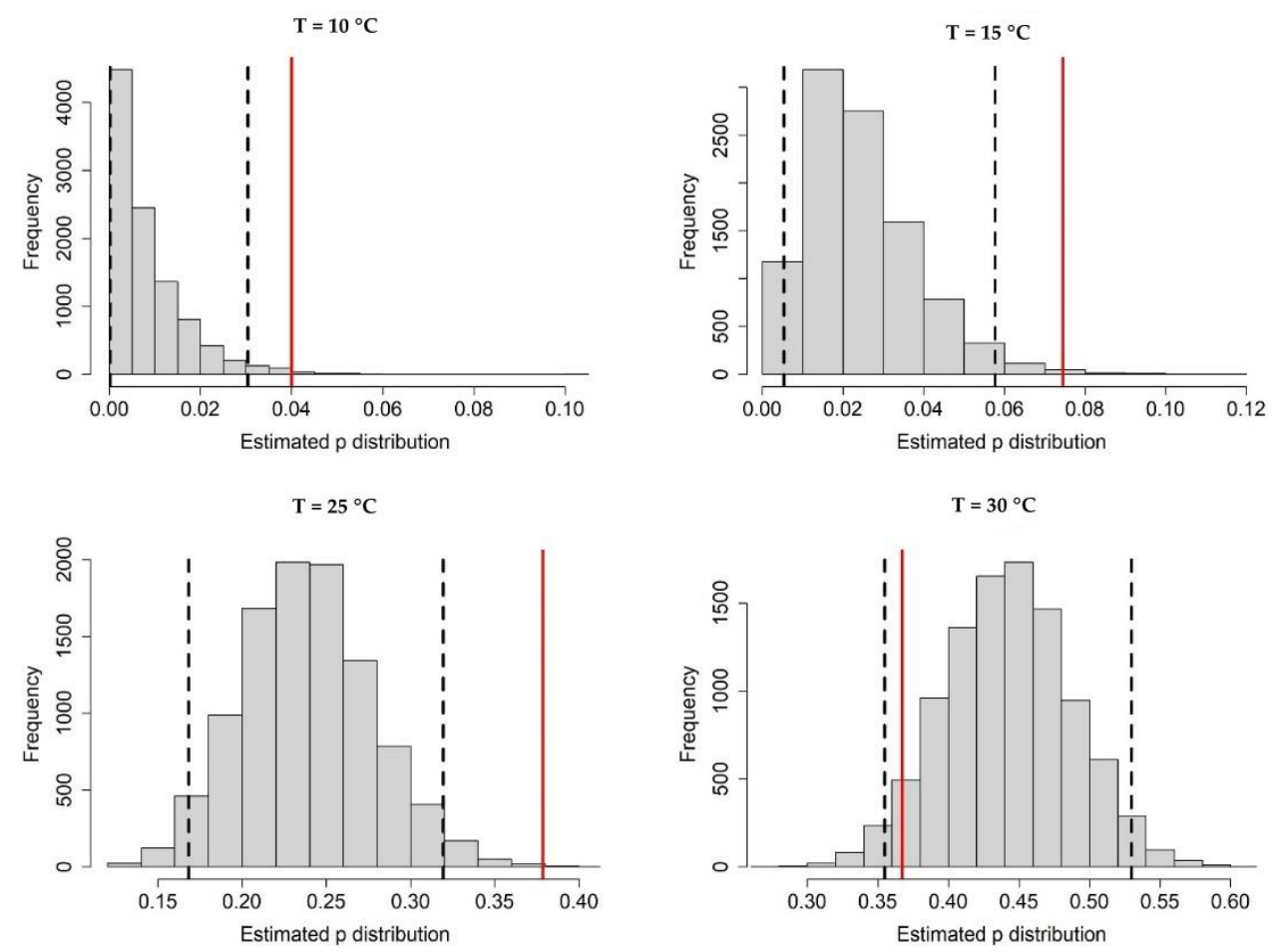

Figure A2. Estimated posterior distributions of $\mathrm{P}_{\mathrm{E}}(\mathrm{T})$, the egg hatching rate at $10,15,25$, and $30{ }^{\circ} \mathrm{C}$. Dashed black lines represent the 2.5 and 97.5 quantiles. Solid red lines represent the average value for subtropical Ae. albopictus.
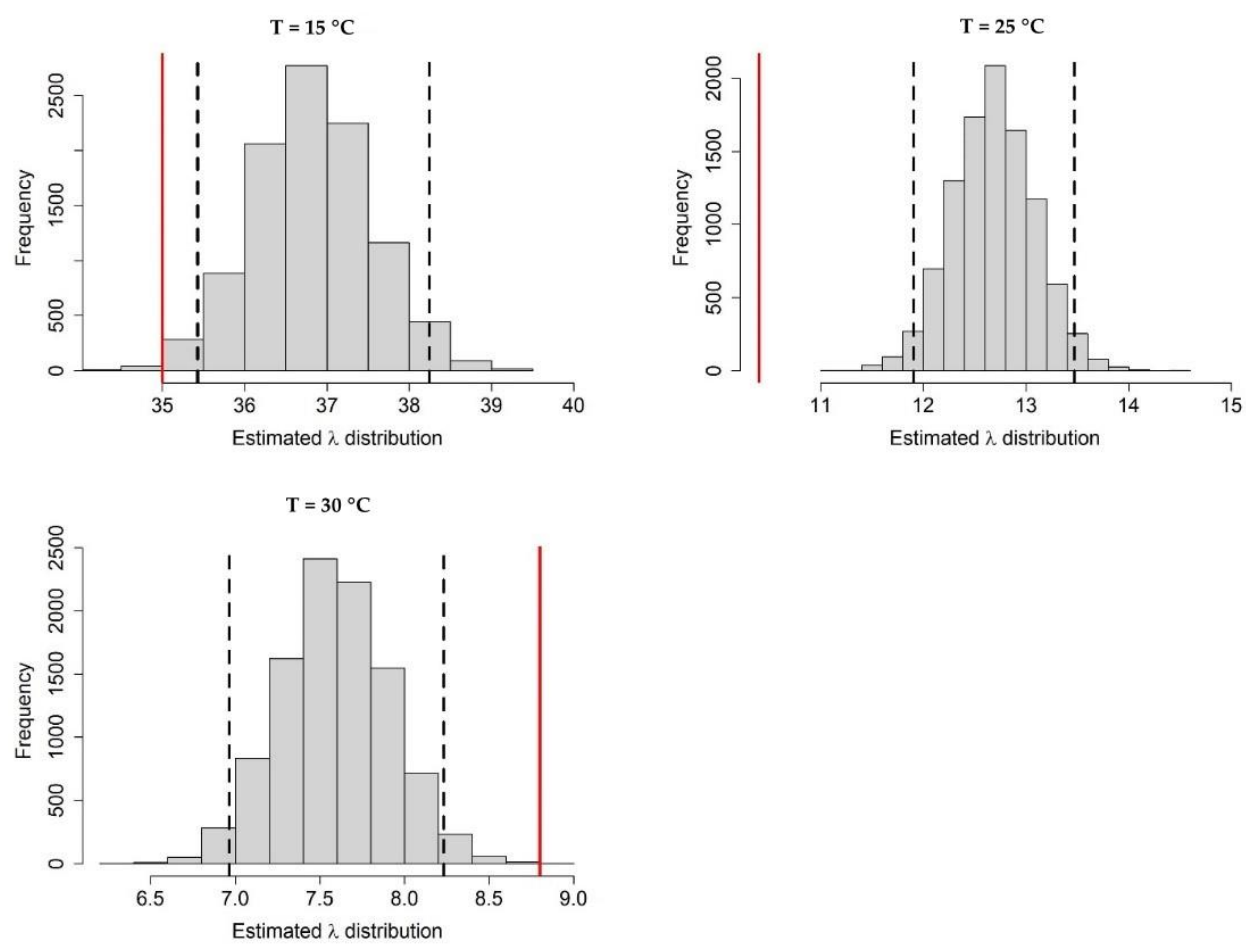

Figure A3. Estimated posterior distributions of $\Lambda_{\mathrm{L} 1-\mathrm{A}}(\mathrm{T})$, the average duration (days) of development from $\mathrm{L} 1$ to $\mathrm{A}$ at 15,25 , and $30^{\circ} \mathrm{C}$. Dashed black lines represent the 2.5 and 97.5 quantiles. Solid red lines represent the average value for subtropical Ae. albopictus. 

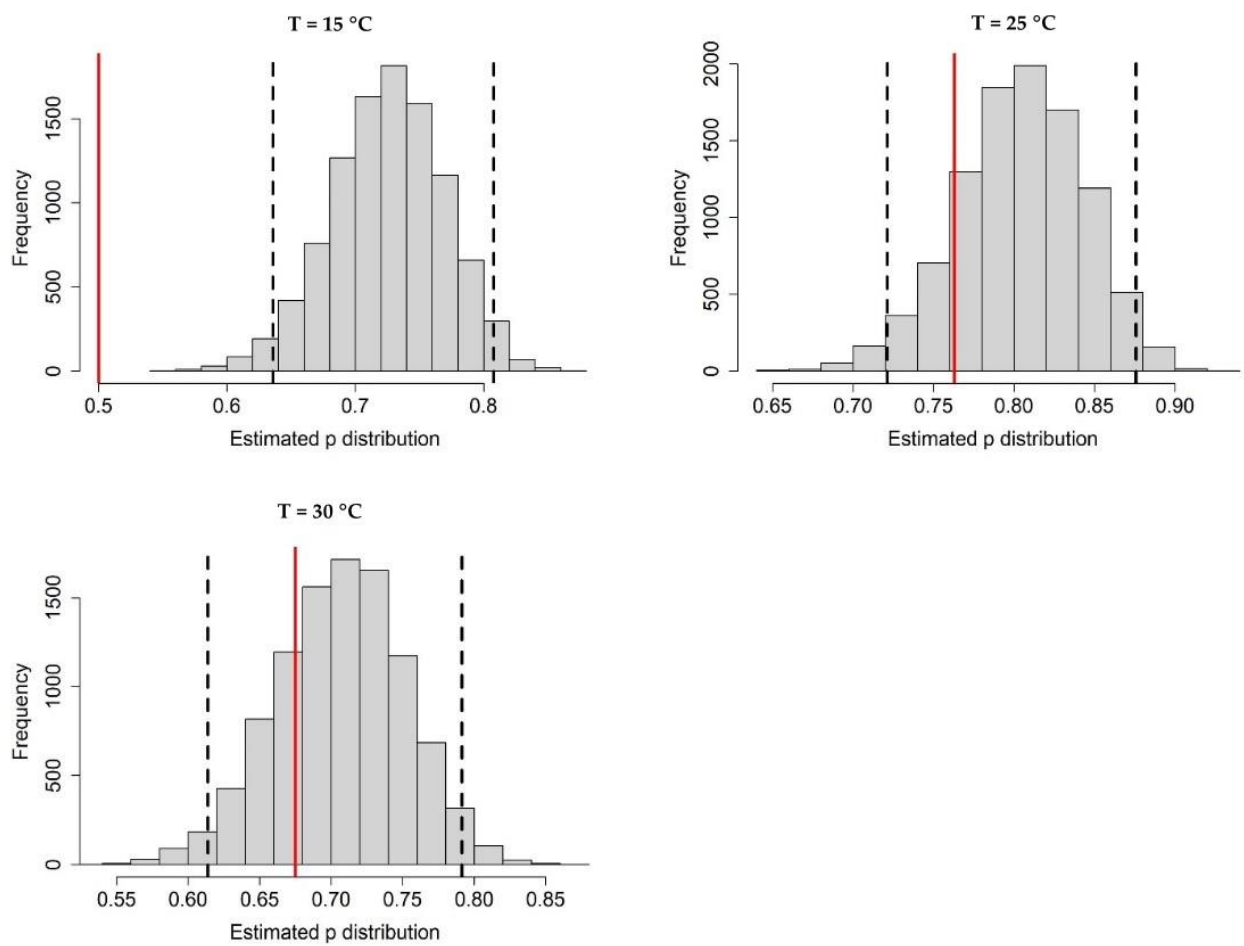

Figure A4. Estimated posterior distributions of $\mathrm{P}_{\mathrm{L} 1-\mathrm{A}}(\mathrm{T})$, the survival rate from L1 to A at 15, 25, and $30{ }^{\circ} \mathrm{C}$. Dashed black lines represent the 2.5 and 97.5 quantiles. Solid red lines represent the average value for subtropical Ae. albopictus.
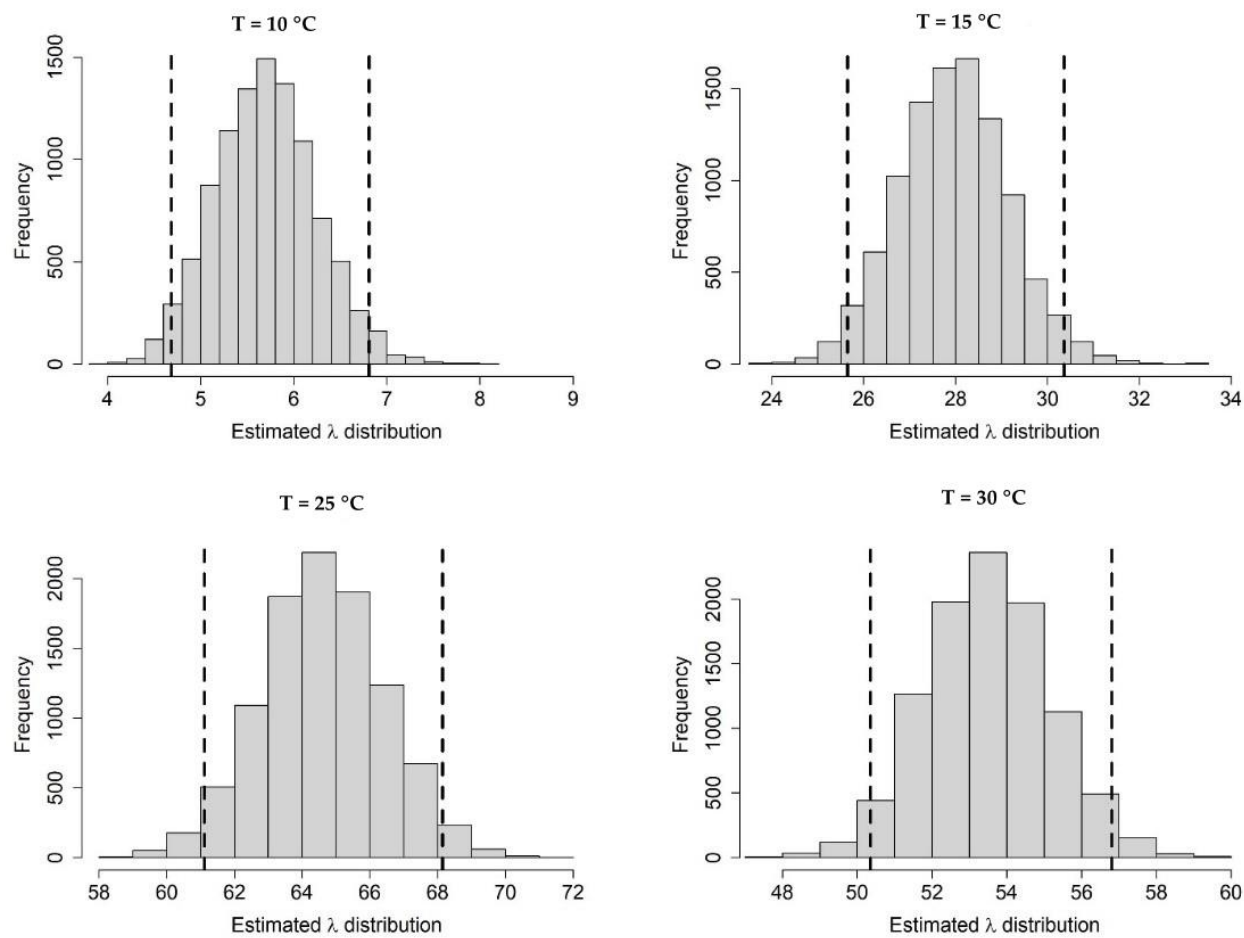

Figure A5. Estimated posterior distributions of $\Lambda_{\mathrm{A}}(\mathrm{T})$, the average adult female longevity (days) at 10, 15,25 , and $30{ }^{\circ} \mathrm{C}$. Dashed black lines represent the 2.5 and 97.5 quantiles. 

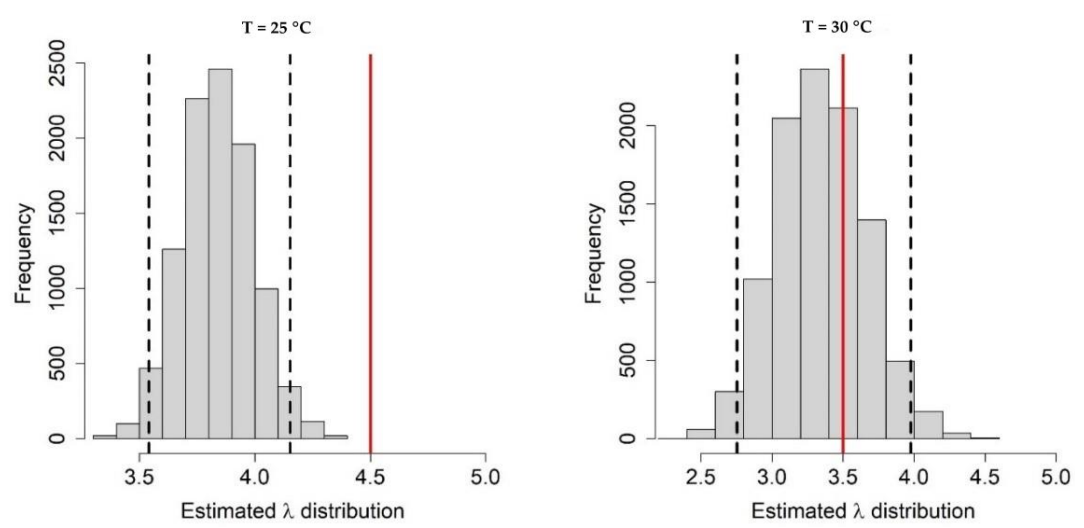

Figure A6. Estimated posterior distributions of $\Lambda_{\mathrm{G}}(\mathrm{T})$, the average duration of gonotrophic cycle at 25 and $30{ }^{\circ} \mathrm{C}$. Dashed black lines represent the 2.5 and 97.5 quantiles. Solid red lines represent the average value for subtropical Ae. albopictus.
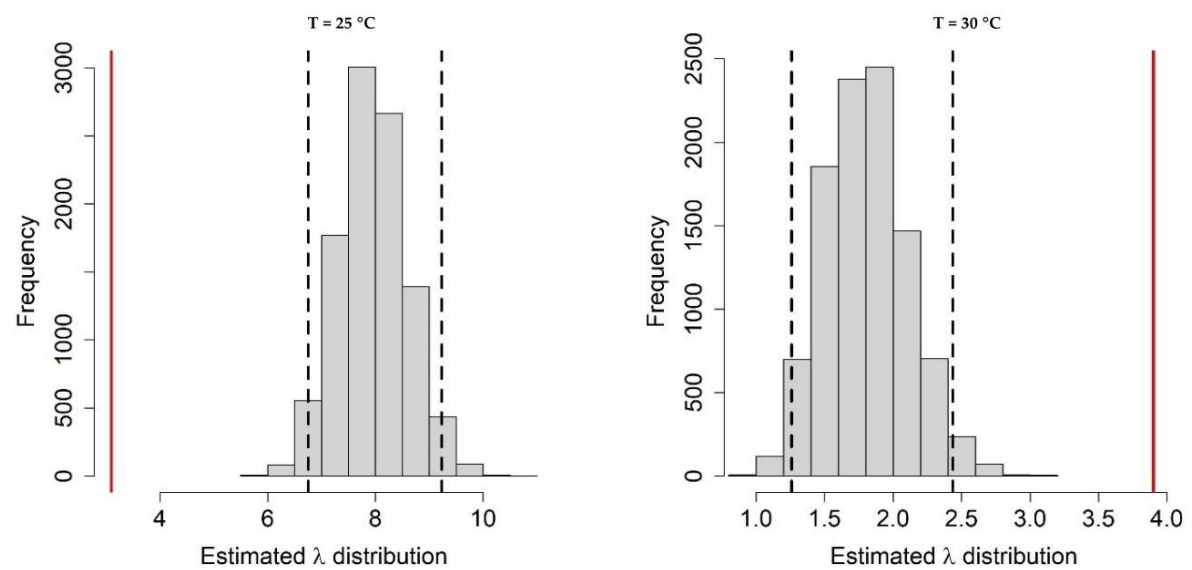

Figure A7. Estimated posterior distributions of $\Lambda_{\mathrm{NG}}(\mathrm{T})$, the number of gonotrophic cycles completed on average by a female mosquito at 25 and $30^{\circ} \mathrm{C}$. Dashed black lines represent the 2.5 and 97.5 quantiles. Solid red lines represent the average value for subtropical Ae. albopictus.
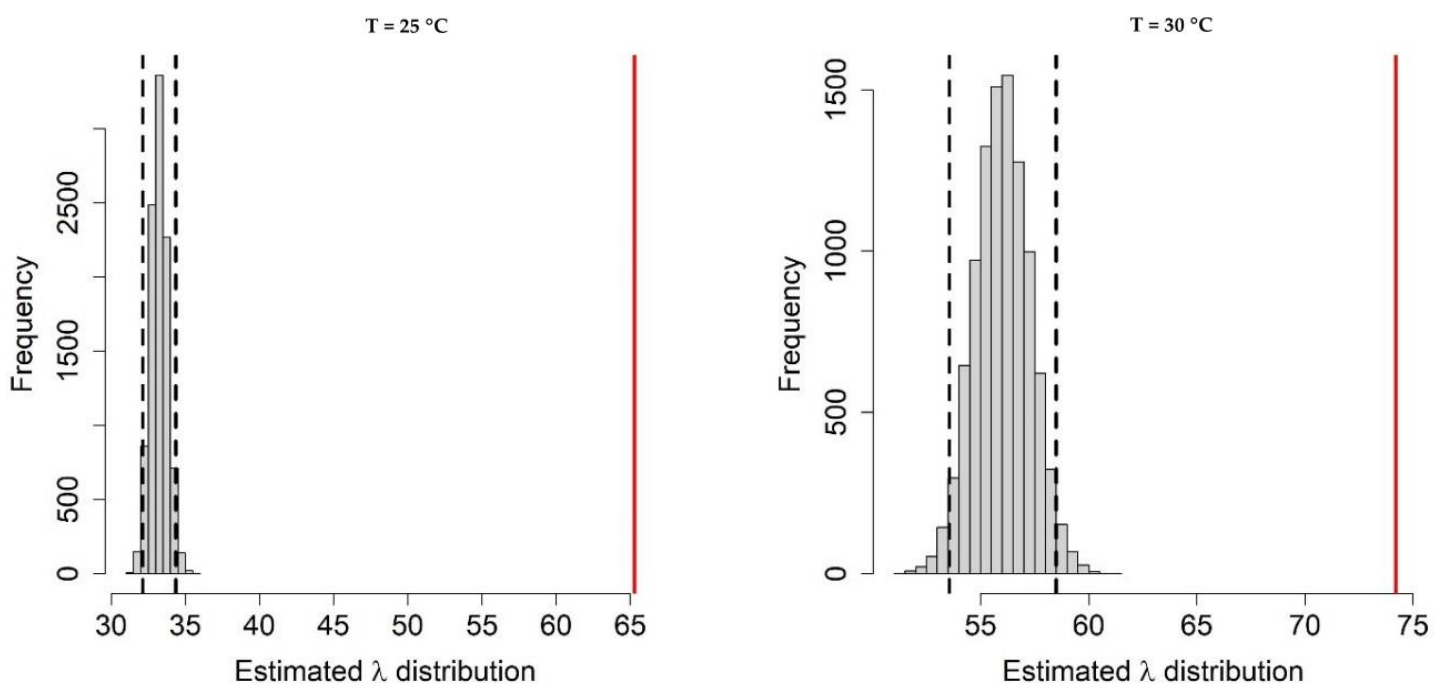

Figure A8. Estimated posterior distributions of $\Lambda_{\mathrm{NE}}(\mathrm{T})$, the number of eggs laid on average by a female mosquito at 25 and $30{ }^{\circ} \mathrm{C}$ for each gonotrophic cycle. Dashed black lines represent the 2.5 and 97.5 quantiles. Solid red lines represent the average value for subtropical Ae. albopictus. 
Appendix A.2. Adult Survival

We modeled adult survival $S$ as age dependent according to a Weibull function

$$
S(t)=\exp \left(-\frac{a}{g} \cdot t^{g}\right)
$$

where $t$ is the age and $a$ and $g$ are free parameters estimated by a least-squares method.

\section{Appendix A.3. Population Dynamics Simulation}

We simulated the life history of 1000 temperate initial eggs at 25 and $30{ }^{\circ} \mathrm{C}$ according to our estimates. More specifically, we run 1000 simulations for each temperature $T \in\{25,30\}$, and for each of them, we drew the number of hatching eggs $e$ and the time of emergence from $P_{E}(T)$ and $\Lambda_{E}(T)$, respectively. Subsequently, the number of emerging adults $a(a \leq e)$ and their time of development was drawn from $\mathrm{P}_{\mathrm{L} 1-\mathrm{A}}(\mathrm{T})$ and $\Lambda_{\mathrm{L} 1-\mathrm{A}}(\mathrm{T})$. Finally, $a / 2$ (only females) adults laid $n$ eggs for each gonotrophic cycle $c$, with $n$ and $c$ drawn from $\Lambda_{\mathrm{NE}}(\mathrm{T})$ and $\Lambda_{\mathrm{NG}}(\mathrm{T})$ respectively, and they live for $l$ days, with $l$ extracted from $\Lambda_{\mathrm{A}}(\mathrm{T})$.

Figures A9 and A10 show the distributions, for the 1000 simulations, of the above-mentioned quantities of interest.
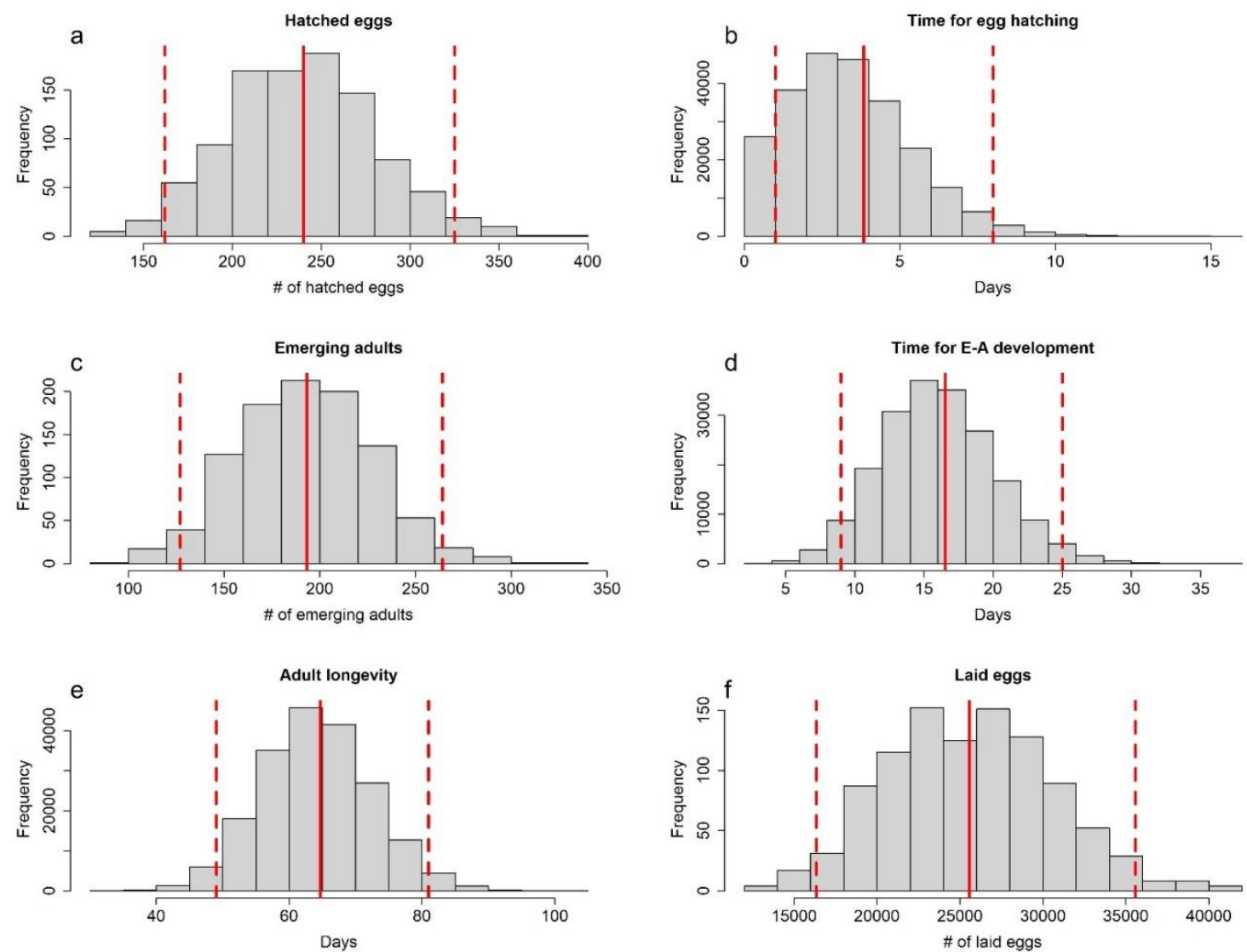

Figure A9. Distributions of quantities of interest for simulated (1000 simulations) life history of 1000 initial eggs at $25^{\circ} \mathrm{C}$. (a) Number of hatched eggs; (b) time for egg development; (c) number of emerging adults; (d) time of development from the egg stage; (e) adult longevity; (f) total number of eggs laid by all females. Dashed red lines represent the 2.5 and 97.5 quantiles, solid red lines represent the average value. 

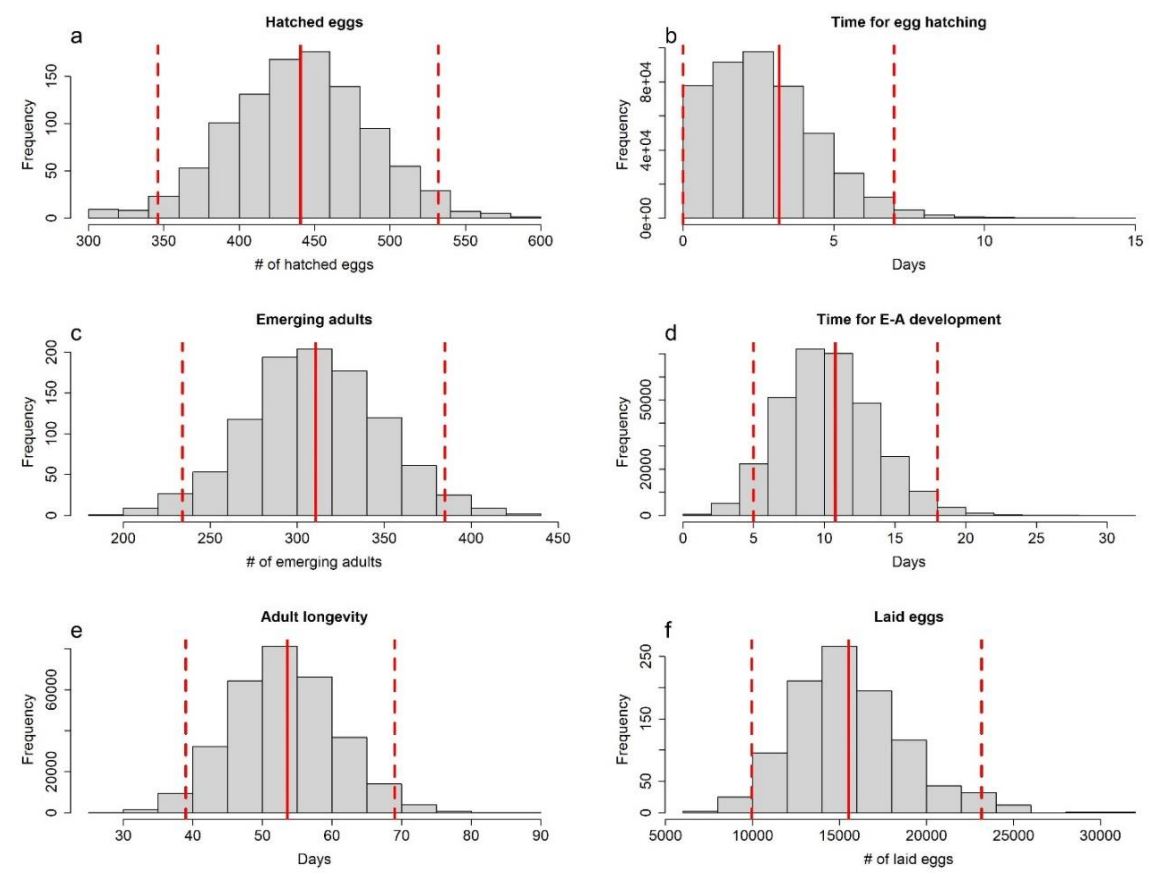

Figure A10. Distributions of quantities of interest for simulated (1000 simulations) life history of 1000 initial eggs at $30^{\circ} \mathrm{C}$. (a) Number of hatched eggs; (b) time for egg development; (c) number of emerging adults; (d) time of development from the egg stage; (e) adult longevity; (f) total number of eggs laid by all females. Dashed red lines represent the 2.5 and 97.5 quantiles, solid red lines represent the average value.

\section{References}

1. European Centre for Disease Prevention and Control. Guidelines for the Surveillance of Invasive Mosquitoes in Europe; ECDC: Stockholm, Sweden, 2012; ISBN 978-92-9193-378-5.

2. Medlock, J.M.; Hansford, K.M.; Schaffner, F.; Versteirt, V.; Hendrickx, G.; Zeller, H.; Van Bortel, W. A review of the invasive mosquitoes in Europe: Ecology, public health risks, and control options. Vector Borne Zoonotic Dis. 2012, 12, 435-447. [CrossRef] [PubMed]

3. European Centre for Disease Prevention and Control Mosquito Maps. Available online: https://ecdc.europa. eu/en/disease-vectors/surveillance-and-disease-data/mosquito-maps (accessed on 1 September 2020).

4. Gasperi, G.; Bellini, R.; Malacrida, A.R.; Crisanti, A.; Dottori, M.; Aksoy, S. A New Threat Looming over the Mediterranean Basin: Emergence of Viral Diseases Transmitted by Aedes albopictus Mosquitoes. PLoS Negl. Trop. Dis. 2012, 6, e1836. [CrossRef] [PubMed]

5. Pereira-dos-Santos, T.; Roiz, D.; Lourenço-de-Oliveira, R.; Paupy, C. A Systematic Review: Is Aedes albopictus an Efficient Bridge Vector for Zoonotic Arboviruses? Pathogens 2020, 9, 266. [CrossRef] [PubMed]

6. Rezza, G.; Nicoletti, L.; Angelini, R.; Romi, R.; Finarelli, A.; Panning, M.; Cordioli, P.; Fortuna, C.; Boros, S.; Magurano, F.; et al. Infection with chikungunya virus in Italy: An outbreak in a temperate region. Lancet 2007, 370, 1840-1846. [CrossRef]

7. Venturi, G.; Luca, M.D.; Fortuna, C.; Remoli, M.E.; Riccardo, F.; Severini, F.; Toma, L.; Manso, M.D.; Benedetti, E.; Caporali, M.G.; et al. Detection of a chikungunya outbreak in Central Italy, August to September 2017. Eurosurveillance 2017, 22, 17-00646. [CrossRef]

8. Delisle, E.; Rousseau, C.; Broche, B.; Leparc-Goffart, I.; L'Ambert, G.; Cochet, A.; Prat, C.; Foulongne, V.; Ferré, J.B.; Catelinois, O.; et al. Chikungunya outbreak in Montpellier, France, September to October 2014. Eurosurveillance 2015, 20, 21108. [CrossRef]

9. Giron, S.; Franke, F.; Decoppet, A.; Cadiou, B.; Travaglini, T.; Thirion, L.; Durand, G.; Jeannin, C.; L'Ambert, G.; Grard, G.; et al. Vector-borne transmission of Zika virus in Europe, southern France, August 2019. Eurosurveillance 2019, 24, 1900655. [CrossRef]

10. Gjenero-Margan, I.; Aleraj, B.; Krajcar, D.; Lesnikar, V.; Klobučar, A.; Pem-Novosel, I.; Kurečić-Filipović, S.; Komparak, S.; Martić, R.; Đuričić, S.; et al. Autochthonous dengue fever in Croatia, August-September 2010. Eurosurveillance 2011, 16, 19805. [CrossRef] 
11. Lazzarini, L.; Barzon, L.; Foglia, F.; Manfrin, V.; Pacenti, M.; Pavan, G.; Rassu, M.; Capelli, G.; Montarsi, F.; Martini, S.; et al. First autochthonous dengue outbreak in Italy, August 2020. Eurosurveillance 2020, 25, 2001606. [CrossRef]

12. Marchand, E.; Prat, C.; Jeannin, C.; Lafont, E.; Bergmann, T.; Flusin, O.; Rizzi, J.; Roux, N.; Busso, V.; Deniau, J.; et al. Autochthonous case of dengue in France, October 2013. Eurosurveillance 2013, 18, 20661. [CrossRef]

13. Monge, S.; García-Ortúzar, V.; López Hernández, B.; Lopaz Pérez, M.Á.; Delacour-Estrella, S.; Sánchez-Seco, M.P.; Fernández Martinez, B.; García San Miguel, L.; García-Fulgueiras, A.; Sierra Moros, M.J. Characterization of the first autochthonous dengue outbreak in Spain (August-September 2018). Acta Trop. 2020, 205, 105402. [CrossRef] [PubMed]

14. Brady, O.J.; Golding, N.; Pigott, D.M.; Kraemer, M.U.G.; Messina, J.P.; Reiner, R.C., Jr.; Scott, T.W.; Smith, D.L.; Gething, P.W.; Hay, S.I. Global temperature constraints on Aedes aegypti and Ae. albopictus persistence and competence for dengue virus transmission. Parasit. Vectors 2014, 7, 338. [CrossRef] [PubMed]

15. Caminade, C.; Medlock, J.M.; Ducheyne, E.; McIntyre, K.M.; Leach, S.; Baylis, M.; Morse, A.P. Suitability of European climate for the Asian tiger mosquito Aedes albopictus: Recent trends and future scenarios. J. R. Soc. Interface 2012, 9, 2708-2717. [CrossRef] [PubMed]

16. Fischer, D.; Thomas, S.M.; Neteler, M.; Tjaden, N.B.; Beierkuhnlein, C. Climatic suitability of Aedes albopictus in Europe referring to climate change projections: Comparison of mechanistic and correlative niche modelling approaches. Eurosurveillance 2014, 19, 20696. [CrossRef]

17. Kraemer, M.U.G.; Reiner, R.C.; Brady, O.J.; Messina, J.P.; Gilbert, M.; Pigott, D.M.; Yi, D.; Johnson, K.; Earl, L.; Marczak, L.B.; et al. Past and future spread of the arbovirus vectors Aedes aegypti and Aedes albopictus. Nat. Microbiol. 2019, 4, 854-863. [CrossRef]

18. Delatte, H.; Gimonneau, G.; Triboire, A.; Fontenille, D. Influence of temperature on immature development, survival, longevity, fecundity, and gonotrophic cycles of Aedes albopictus, vector of chikungunya and dengue in the Indian Ocean. J. Med. Entomol. 2009, 46, 33-41. [CrossRef]

19. Loetti, V.; Schweigmann, N.; Burroni, N. Development rates, larval survivorship and wing length of Culex pipiens (Diptera: Culicidae) at constant temperatures. J. Nat. Hist. 2011, 45, 2203-2213. [CrossRef]

20. Marini, G.; Arnoldi, D.; Baldacchino, F.; Capelli, G.; Guzzetta, G.; Merler, S.; Montarsi, F.; Rizzoli, A.; Rosà, R. First report of the influence of temperature on the bionomics and population dynamics of Aedes koreicus, a new invasive alien species in Europe. Parasit. Vectors 2019, 12, 524. [CrossRef]

21. Reinhold, J.M.; Lazzari, C.R.; Lahondère, C. Effects of the Environmental Temperature on Aedes aegypti and Aedes albopictus Mosquitoes: A Review. Insects 2018, 9, 158. [CrossRef]

22. Reuss, F.; Wieser, A.; Niamir, A.; Bálint, M.; Kuch, U.; Pfenninger, M.; Müller, R. Thermal experiments with the Asian bush mosquito (Aedes japonicus japonicus) (Diptera: Culicidae) and implications for its distribution in Germany. Parasit. Vectors 2018, 11, 81. [CrossRef]

23. Alto, B.W.; Juliano, S.A. Precipitation and Temperature Effects on Populations of Aedes albopictus (Diptera: Culicidae): Implications for Range Expansion. J. Med. Entomol. 2001, 38, 646-656. [CrossRef] [PubMed]

24. Alto, B.W.; Juliano, S.A. Temperature Effects on the Dynamics of Aedes albopictus (Diptera: Culicidae) Populations in the Laboratory. J. Med. Entomol. 2001, 38, 548-556. [CrossRef] [PubMed]

25. Monteiro, L.C.C.; de Souza, J.R.B.; de Albuquerque, C.M.R. Eclosion rate, development and survivorship of Aedes albopictus (Skuse) (Diptera: Culicidae) under different water temperatures. Neotrop. Entomol. 2007, 36, 966-971. [CrossRef] [PubMed]

26. Brugueras, S.; Fernández-Martínez, B.; Martínez-de la Puente, J.; Figuerola, J.; Porro, T.M.; Rius, C.; Larrauri, A.; Gómez-Barroso, D. Environmental drivers, climate change and emergent diseases transmitted by mosquitoes and their vectors in southern Europe: A systematic review. Environ. Res. 2020, 191, 110038. [CrossRef] [PubMed]

27. Roche, B.; Léger, L.; L'Ambert, G.; Lacour, G.; Foussadier, R.; Besnard, G.; Barré-Cardi, H.; Simard, F.; Fontenille, D. The Spread of Aedes albopictus in Metropolitan France: Contribution of Environmental Drivers and Human Activities and Predictions for a Near Future. PLoS ONE 2015, 10, e0125600. [CrossRef]

28. Pluskota, B.; Jöst, A.; Augsten, X.; Stelzner, L.; Ferstl, I.; Becker, N. Successful overwintering of Aedes albopictus in Germany. Parasitol. Res. 2016, 115, 3245-3247. [CrossRef]

29. Brady, O.J.; Johansson, M.A.; Guerra, C.A.; Bhatt, S.; Golding, N.; Pigott, D.M.; Delatte, H.; Grech, M.G.; Leisnham, P.T.; Maciel-de-Freitas, R.; et al. Modelling adult Aedes aegypti and Aedes albopictus survival at different temperatures in laboratory and field settings. Parasit. Vectors 2013, 6, 351. [CrossRef] 
30. Guzzetta, G.; Montarsi, F.; Baldacchino, F.A.; Metz, M.; Capelli, G.; Rizzoli, A.; Pugliese, A.; Rosà, R.; Poletti, P.; Merler, S. Potential Risk of Dengue and Chikungunya Outbreaks in Northern Italy Based on a Population Model of Aedes albopictus (Diptera: Culicidae). PLoS Negl. Trop. Dis. 2016, 10, e0004762. [CrossRef]

31. Manica, M.; Guzzetta, G.; Poletti, P.; Filipponi, F.; Solimini, A.; Caputo, B.; Torre, A.d.; Rosà, R.; Merler, S. Transmission dynamics of the ongoing chikungunya outbreak in Central Italy: From coastal areas to the metropolitan city of Rome, summer 2017. Eurosurveillance 2017, 22, 17-00685. [CrossRef]

32. Marini, G.; Guzzetta, G.; Baldacchino, F.; Arnoldi, D.; Montarsi, F.; Capelli, G.; Rizzoli, A.; Merler, S.; Rosà, R. The effect of interspecific competition on the temporal dynamics of Aedes albopictus and Culex pipiens. Parasit. Vectors 2017, 10, 102. [CrossRef]

33. Pasquali, S.; Mariani, L.; Calvitti, M.; Moretti, R.; Ponti, L.; Chiari, M.; Sperandio, G.; Gilioli, G. Development and calibration of a model for the potential establishment and impact of Aedes albopictus in Europe. Acta Trop. 2020, 202, 105228. [CrossRef] [PubMed]

34. Poletti, P.; Messeri, G.; Ajelli, M.; Vallorani, R.; Rizzo, C.; Merler, S. Transmission Potential of Chikungunya Virus and Control Measures: The Case of Italy. PLoS ONE 2011, 6, e18860. [CrossRef] [PubMed]

35. Tran, A.; L'Ambert, G.; Lacour, G.; Benoît, R.; Demarchi, M.; Cros, M.; Cailly, P.; Aubry-Kientz, M.; Balenghien, T.; Ezanno, P. A Rainfall- and Temperature-Driven Abundance Model for Aedes albopictus Populations. Int. J. Environ. Res. Public. Health 2013, 10, 1698-1719. [CrossRef] [PubMed]

36. Roiz, D.; Rosà, R.; Arnoldi, D.; Rizzoli, A. Effects of Temperature and Rainfall on the Activity and Dynamics of Host-Seeking Aedes albopictus Females in Northern Italy. Vector Borne Zoonotic Dis. 2010, 10, 811-816. [CrossRef] [PubMed]

37. Rosso, F.; Tagliapietra, V.; Albanese, D.; Pindo, M.; Baldacchino, F.; Arnoldi, D.; Donati, C.; Rizzoli, A. Reduced diversity of gut microbiota in two Aedes mosquitoes species in areas of recent invasion. Sci. Rep. 2018, 8, 16091. [CrossRef]

38. Gilks, W.R.; Richardson, S.; Spiegelhalter, D. Markov Chain Monte Carlo in Practice; Chapman \& Hall: London, UK, 1996; ISBN 0-412-05551-1.

39. Cunze, S.; Kochmann, J.; Koch, L.K.; Klimpel, S. Aedes albopictus and Its Environmental Limits in Europe. PLoS ONE 2016, 11, e0162116. [CrossRef]

40. Meteotrentino Meteotrentino. Available online: www.meteotrentino.it (accessed on 31 August 2020).

41. Mordecai, E.A.; Caldwell, J.M.; Grossman, M.K.; Lippi, C.A.; Johnson, L.R.; Neira, M.; Rohr, J.R.; Ryan, S.J.; Savage, V.; Shocket, M.S.; et al. Thermal biology of mosquito-borne disease. Ecol. Lett. 2019, 22, 1690-1708. [CrossRef]

42. European Centre for Disease Prevention and Control. Vector Control with a Focus on Aedes Aegypti and Aedes Albopictus Mosquitoes: Literature Review and Analysis of Information; ECDC: Stockholm, Sweden, 2017; ISBN 978-92-9498-095-3.

43. Erguler, K.; Pontiki, I.; Zittis, G.; Proestos, Y.; Christodoulou, V.; Tsirigotakis, N.; Antoniou, M.; Kasap, O.E.; Alten, B.; Lelieveld, J. A climate-driven and field data-assimilated population dynamics model of sand flies. Sci. Rep. 2019, 9, 2469. [CrossRef]

44. Medley, K.A.; Westby, K.M.; Jenkins, D.G. Rapid local adaptation to northern winters in the invasive Asian tiger mosquito Aedes albopictus: A moving target. J. Appl. Ecol. 2019, 56, 2518-2527. [CrossRef]

45. Erguler, K.; Smith-Unna, S.E.; Waldock, J.; Proestos, Y.; Christophides, G.K.; Lelieveld, J.; Parham, P.E. Large-Scale Modelling of the Environmentally-Driven Population Dynamics of Temperate Aedes albopictus (Skuse). PLoS ONE 2016, 11, e0149282. [CrossRef]

46. Neteler, M.; Roiz, D.; Rocchini, D.; Castellani, C.; Rizzoli, A. Terra and Aqua satellites track tiger mosquito invasion: Modelling the potential distribution of Aedes albopictus in north-eastern Italy. Int. J. Health Geogr. 2011, 10, 49. [CrossRef] [PubMed]

Publisher's Note: MDPI stays neutral with regard to jurisdictional claims in published maps and institutional affiliations. 